\title{
Comparative Analysis of Differences and Evolution of Hemorrhoidectomy Techniques
}

\author{
Nayara Lobo Coelho ${ }^{1}$, Rodolpho Cesar Oliveira Mellem Kairala', \\ Bruna Lemos Silva', Afrânio Faria Lemos ${ }^{2}$, Danilo Rocha Chavez Zambrana', \\ Caio Cesar Faciroli Contin Silva ${ }^{3}$, Ana Carolina Arantes ${ }^{4}$, \\ Vergílio Pereira Carvalho ${ }^{5}$, Silvio de Almeida-Júnior ${ }^{6^{*}}$ and Bruna Lima Daher ${ }^{1}$ \\ ${ }^{1}$ Santa Casa de Misericórdia de Franca Foundation, Brazil. \\ ${ }^{2}$ Hospital Guilherme Álvaro, Brazil. \\ ${ }^{3}$ Santa Casa de Misericórdia de Limeira Foundation, Brazil. \\ ${ }^{4}$ Franca Municipal University Center (Uni-FACEF), Brazil. \\ ${ }^{5}$ University of Rio Verde (UniRV), Brazil. \\ ${ }^{6}$ Department of Health Promotion, University of Franca (UNIFRAN), Brazil.
}

Authors' contributions

This work was carried out in collaboration among all the authors. The study project, protocol writing, data management, bibliographic reviews and standardization were carried out by the authors on an equal basis. All authors read and approved the final manuscript.

Article Information

DOI: $10.9734 / A R R B / 2020 / v 35 i 630236$ Editor(s):

(1) Dr. Viduranga Y. Waisundara, Australian College of Business \& Technology, Sri Lanka.
Reviewers:

(1) Fatma Ahmed Ali-Eldin, Ain Shams University, Egypt. (2) Kiril Slaveykov I-st, Trakia University, Bulgaria. (3) Akhmad Rifai, Politeknik Negeri Ujung Pandang, Indonesia. Complete Peer review History: http://www.sdiarticle4.com/review-history/58712

Review Article

Received 23 April 2020

Accepted 29 June 2020

Published 07 July 2020

\section{ABSTRACT}

Aim: To review from the literature, in a narrative way, techniques used for hemorrhoidectomy as well as benefits and criticisms about the procedures.

Methodology: For this purpose, a descriptive literary review was carried out for the construction of the work. In view of what is found, it is possible to assess this according to an epidemiological study conducted in the United States.

Results: Hemorrhoid disease is a very common condition, occurring in $4.4 \%$ of adults, with a maximum prevalence between 45 and 65 years. The etiology of hemorrhoids is still unknown. Hemorrhoidectomy is believed to be the best treatment option for symptomatic hemorrhoid disease 
grade III and IV. The techniques used present advantages and disadvantages for the patient, since it will depend on the surgeon to choose the best approach and surgical procedure.

Conclusion: It is observed that more risk and benefit assessments are needed than the technique used in hemorrhoidectomy, based on randomized studies with a significant number of patients included in the study.

Keywords: Colorectal surgery; colprology; hemorrhoids; surgical clinic; surgical techniques.

\section{ABBREVIATIONS}

$H D$ : Hemorrhoidal Disease

HPP : Hemorrhoid Prolapse Procedure

THD : Transanal Hemorrhoidal Dearterialization

\section{INTRODUCTION}

Hemorrhoidal disease (HD) is a very common condition, which occurs in $4.4 \%$ of adults with a higher prevalence in the age group between 45 and 65 years of age, with a decrease after 65 years of age, being uncommon before 20 years [1]. It is verified that the hemorrhoidal nipples are constituted in normal anatomical regions found in human beings, in contrast, HD appears when these nipples prolapse, inflame and produce symptoms [2].

The exact etiology of the disease remains unknown. Hemorrhoids are vascular cushions and not varicose veins, promoting the maintenance of mucosal and submucosal adherence to the internal sphincter, in addition to supporting the blood vessels of the submucosa and cushioning the passage of feces. The hypothesis of the aid of hemorrhoids in the occlusion of the anal canal is reinforced by the existence of arteriovenous anastomoses that would provide blood supply much greater than that needed for local tissue nutrition. At rest, the patient would experience engorgement of the cushions and better occlusion of the anal canal $[1,3]$.

Hemorrhoids can be classified, from the anatomical point of view, into internal, external and mixed, according to the hemorrhoidal plexus affected. In this sense, when the symptoms come from vascular dilations originating above the pectineus line, internal hemorrhoids are called, when in addition to the pectineus line, they are called external; mixed hemorrhoids are those in which the two plexuses are involved [2]. Internal hemorrhoids can be classified according to the magnitude of the prolapse. Grade I hemorrhoids (without prolapse, only with bleeding). Grade II hemorrhoids (prolapse with spontaneous reduction); Grade III hemorrhoids (prolapse requiring digital reduction). Grade IV hemorrhoids (prolapsed and cannot be reduced or strangled) [4].

There is a notable diversity of invasive nonsurgical outpatient procedures found in the literature, in which the hemorrhoidal nipples are not resected, including: ligation, sclerotherapy, cryotherapy, infrared photocoagulation, diathermy and electrocoagulation [5,6]. These procedures can be used in grade I HD, some grade II and well selected grade III [7] cases. Hemorrhoidectomy is defined by the removal of internal and external hemorrhoidal nipples, with subsequent fixation of adjacent tissues, mitigating the symptoms presented by the patient with HD [2].

Hemorrhoidectomy is the best treatment option for grade III and grade IV HD [8], or in patients with less severe hemorrhoids who do not respond to conservative treatment and even if hemorrhoids are complicated with strangulation, or are associated with ulcers, fissures, fistulas, symptomatic external hemorrhoids or large anal plicomas $[9,10]$.

Surgical techniques for HD correction are divided into hemorrhoidectomy and hemorrhoidopexy, namely: technique open to Milligan-Morgan, technique closed to Fergunson, mixed techniques, between hemorrhoidectomies and Hemorrhoid Prolapse Procedure (HPP) and Transanal Hemorrhoidal Dearterialization (THD). Likewise, in addition to the traditional use of the scalpel, laser surgeries (CO2 laser and Nd:YAG laser) can also be performed, or with Ligasure, or harmonic scalpel $[3,11,12]$.

Differentiate the main techniques for the treatment of hemorrhoidal disease, namely open, closed, mixed and amputative techniques. Associate the hemorrhoidectomy techniques regarding recent and late complications, the length of hospital stays and the patient's return to 
their work activities. Understand in a subjective analysis if there is any superiority of any technique in relation to the final outcome.

\section{METHODOLOGY}

This is a quantitative study based on a review of the narrative literature, in which the following referential databases were used: Web of Science; Capes Periodical; Scopus; SciELO magazines; Social Sciences Research Network (SSRN); PubMed and MEDLINE Complete. Articles, magazines and journals were searched with the following descriptors: hemorrhoidectomy; hemorrhoids; colorectal surgery.

The study was characterized by its comparative character, in which a relationship was made between the data in the literature, differentiating the hemorrhoidectomy techniques, emphasizing the postoperative results. In addition, the collection of this information was also achieved by observing the following national bibliographic sources in public health: Portal of the State Department of Health and Virtual Health Library. Likewise, the main coloproctology textbooks were used, which compared the techniques hemorrhoidectomy and hemorrhoidopexy.

The same presented difficulties, because it is a little debated subject, being more approached new technologies or still, case reports from something already pre-existing. Thus, given the educational character, the narrative review is intended to compare and differentiate current surgical techniques, we assess early and late postoperative complications.

\section{RESULTS AND DISCUSSION}

Some surgeons have proposed improvements to open and closed techniques. Thus, he agreed to call these techniques improved in semi-closed techniques, which are nothing more than derivations of the original ideas of MilliganMorgan and Fergunson. The most widespread semi-closed techniques among specialists are: Sokol, Ruiz-Moreno, René Obando [13], Parks submucosa [14]; however, they are not characterized by the scientific and surgical community as new techniques. One can also mention the Whitehead techniques [15], which provided good results at the time, and the hybrid hemorrhoidectomy (elastic ligation of the internal nipples associated with surgical resection of the external nipples). However, they do not present significant acceptance / utilization rates among surgeons.

It is observed that surgical excision in the form of hemorrhoidectomy has been reported with innumerable complications. The main complications are stenosis, bleeding, infection, recurrence, delayed scarring, fissure in the wound bed, incontinence and fistulas [2]. Despite these complications, hemorrhoidectomy is still considered an effective treatment for third and fourth degree hemorrhoids [16]. In Europe, the open technique or Milligan-Morgan procedure is more frequently practiced, whereas in the USA the most used procedure is closed hemorrhoidectomy by Ferguson and Heaton [17]. However, there are several controversies regarding pain and postoperative complications.

Stapled circumferential hemorrhoidopexy is described by circumferential resection of the mucosa of the lower rectum. This technique has now been approved as an alternative to hemorrhoidectomy to Milligan-Morgan [18]. HPP is a widely recognized technique in the treatment of hemorrhoidal mucosa prolapse, and lately, it is well accepted thanks to the advantages shown in the short-term results, such as reduction postoperative pain, length of stay in the hospital and some complications [19]. However, in recent years, criticism has been directed towards this surgical procedure in terms of higher recurrence rates when compared to conventional techniques [20].

HPP removes an annular and circular band of mucosa and submucosa located above the pectineal line, suspending and fixing the hemorrhoidal vessels, which would additionally suffer interruption of blood flow, persisting the external nipples. Based on the concept itself, the technique is not a hemorrhoidectomy, but a hemorrhoidopexy. Several series have already been illustrated in the world, and currently more than five million surgeries have been performed with this procedure [3].

Milligan-Morgan's open technique is a reference in the coloproctology textbooks and widely disseminated around the world, it is the most used by specialists. The technique consists in the excision of hemorrhoidal tissue, through the skin towards the mucosa, with ligation of its vascular pedicle, keeping the bloody bed of the dissection open so that healing occurs by second intention, repeating this act as many times how many hemorrhoidal nipples to be resected $[21,22]$. 
22 years after the creation of the Milligan-Morgan open technique, the closed technique emerged, considered another exponent in the core of coloproctology. Like the open technique, it has established itself as a classic technique of recurrent use by several specialists in the world [23] which consists of excision of hemorrhoidal tissue, from the skin towards the mucosa, with ligation of the vascular pedicle, in the molds of the Milligan-Morgan technique, however the beds of nipple resections, instead of remaining open, are sutured, approaching the edges, using a monofilament thread, using a continuous suture [22].

Dissection can be achieved with scissors or an electric scalpel. After removal of the nipple, its base is connected with 4-0 absorbable monofilament thread (that is, if it is bulky) or merely sectioned with the electric scalpel, which occurs most of the time. Care must be taken not to respect the mucosa to a large lateral extent due to the risk of stenosis. The closure of the wounds is performed with the same monofilament thread, through continuous suture that includes the two edges of the mucosa and the wound bed, in order to prevent complications such as abscess and fistula [2,24].

As previously described, in the open MilliganMorgan technique, the hemorrhoidal tissue was excised, through the skin felt to the mucosa, with the ligation of its vascular pedicle, keeping the bloody bed of the dissection open for healing by second intention, doing the same successive times as many hemorrhoidal nipples to be respected. On the other hand, there are authors who choose to operate by removing some nipples and leaving some beds open and others closed, to Ferguson [25]. In practice, what is known is that if there is excess skin the bed is sutured, as if it were the closed technique. Fergunson; if there is no skin, the bed is left open for healing by second intention.

From the literature, 2,417 patients underwent hemorrhoidectomy, resulting in 76 complications (3.1\%): 2,014 patients were operated by open technique or Milligan-Morgan (83.3\%), leading to 61 cases of complications (3.0\%); 232 patients were operated on using the closed or Ferguson technique $(9.6 \%)$, leading to 8 complications (3.4\%); and 171 patients were operated by mixed technique, with open and closed beds $(7.1 \%)$, causing 7 complications (4.1\%) [23].

In another study, of a prospective, randomized clinical type, carried out in the surgical unit of the
Liaquat University of Medical and Health Sciences University Hospital, located in Pakistan, the research comprised a sample of 213 patients with grade III or IV hemorrhoids divided into two groups, 110 patients in group A were operated by the Milligan-Morgan technique (open) and 103 patients in group B were operated by the Ferguson technique (closed). The results showed that the mean time of approach in the operating room was significantly longer in group B (31.3 $\pm 4.8 \mathrm{~min})$ compared to group A (25.2 \pm 5.6). The duration of hospitalization and time off work was greater in group A than in group B. Wound healing was faster in group $B$ compared to group $A$. In addition, postoperative pain scores were significantly lower in group $B$ than group $A$ during the first 24 hours [26]. This study concluded that the Ferguson procedure or closed technique has an open advantage with regard to a lower degree of postoperative pain, bleeding, recurrence faster to work, and shorter wound healing time. In contrast, the open technique showed an advantage over complications such as wound dehiscence and anal stenosis $[26,27]$.

In another study carried out at the Coloproctology Service of Hospital do Servidor Público Municipal de São Paulo (HSPM), medical records of patients with HD were analyzed, whose intervention of choice was surgical treatment. Patients who had external or mixed hemorrhoids, hemorrhoidal thrombosis, previous hemorrhoidectomy, associated fissure, fistula or anal condyloma were not selected to compose the sample, resulting in 253 patients with isolated internal hemorrhoids. This sample was subdivided into group 1 , which consisted of patients operated using the conventional hemorrhoidectomy technique $(n=212)$, group 2 of patients operated using the mechanical hemorrhoidopexy technique ( $n=41)$. In Group 1, the techniques used were the Milligan 27 or Mixed Techniques. In Group 2, the patients were operated according to the technique described by Longo and recommended by the International Consensus [18]. From this, the epidemiological profiles, indications, complications, need for surgical reintervention, were retrospectively investigated, through the analysis of medical records, operative time, outpatient discharge and follow-up for each group.

It was found that the average operative time per procedure was 52 minutes (25 to 120 minutes) in Group 1 and 31 minutes (20 to 65 minutes) in Group 2 [28] and the period of outpatient discharge was fixed considering the last 
associated consultation to the surgical procedure in the postoperative period. Consequently, the average time of outpatient discharge recorded for Group 1 was 10 weeks, while in Group 2 it was 6 weeks [28].

In the work carried out at the Surgery Department at Raigmore Hospital in Scotland, with a sample of 777 volunteers in a randomized study, subdividing the groups into: 389 patients undergoing HPP and 388 operated by conventional hemorrhoidectomy, the overall quality of life was better for the group submitted to conventional hemorrhoidectomy in relation to the group that underwent HPP in 24 months. Participants in the hemorrhoidectomy group had fewer symptoms over a 12 to 24-month period, and reported fewer complications in 12 (39/278) and 24 months $(76 / 300)$ compared to the group who had HPP in 12 months (94/295) and in 24 months (134/317) [29]. No difference was observed in the length of stay or in the time of operation between the two groups. What was noted was that hemorrhoidectomy is costeffective in terms of cost-effectiveness compared to hemorrhoidopexy [29]. It was concluded that hemorrhoidopexy was less painful than conventional hemorrhoidectomy and the rates of surgical complications were similar between groups $[2,29]$.

To minimize the discomfort of postoperative pain after conventional hemorrhoidectomy surgery, several alternatives to conventional techniques have been developed, such as circular stapling. A beneficial effect has been reported by several authors using the latter technique, but in a review the use of the stapler device was associated with an increased risk of HD recurrence and rectal prolapse. Consequently, the authors concluded that, today, the conventional excision technique remains the standard treatment. It is inferred that excision can be performed with a cold scalpel, diathermy or electrosurgery, scissors, laser, ultrasonic scalpel or bipolar electrothermal device [30]. The use of scissors or laser compared to diathermy did not provide significant benefits [31]. Conflicting results have been reported in relation to the use of an activated ultrasonic scalpel (Ultracission TM), making definitive conclusions on the subject impossible [32].

A bipolar electrothermal device or Ligasure-TM (Valleylab, Boulder, CO) was introduced in the field of hemorrhoidectomy. In contrast to diathermy or electrocautery, this device uses a very high frequency current, providing hemostasis by denaturing the collagen and elastin in the vessel wall and surrounding connective tissue. It is postulated that the sealing of the hemorrhoidal tissue between the Ligasureforceps is achieved with minimal collateral thermal distribution and limited carbonization of the tissue through the use of active feedback on potency and may result in decreased postprocedure pain compared to conventional surgical techniques [33].

Another study, a randomized controlled trial, was conducted at the Department of Surgery at Dow University Hospital in Karachi, located in Pakistan, from January 2013 to September 2015. A total of 55 patients were included in the study. Patients were randomly allocated to group A (hemorrhoidectomy by LigaSure), 29 cases and group B (hemorrhoidectomy by Milligan-Morgan) 26 cases. The effectiveness of both procedures was compared by operative time, blood loss, wound healing and pain score on the first, day and day immediately after the operation. Of the total of 55 patients, 23 were male and 32 females, the most common age group involved was between 40 and 60 years old, hemorrhoids of the third degree were present in $37(67.3 \%)$ of the patients, while $18(32.7 \%)$ had IV grade hemorrhoids. The study concluded that the efficacy of hemorrhoidectomy by LigaSure is better than the traditional hemorrhoidectomy using the Milligan-Morgan technique, however more clinical trials with a larger sample and longterm follow-up are still required [34].

\section{CONCLUSION}

From what has been reported it is possible to conclude:

- Ferguson's closed hemorrhoidectomy has few clinically measurable advantages over Milligan Morgan's open hemorrhoidectomy in terms of reduced postoperative pain, lower risk of bleeding postoperatively and faster wound healing.

- Recent and older studies show equivalence in complication rates when using open, closed or mixed techniques, in the same way, without statistical significance, even considering associations between men and women.

- Regarding the use of a more recent technique, such as PPH, studies have shown that short-term postoperative results are better. 
- On the other hand, studies with a longer follow-up refute this result, showing that the conventional technique presents superior results in relation to the postoperative aspects and quality of life.

\section{FUNDING}

This study was financed in part by the Coordination for the Improvement of Higher Education Personnel - Brazil (CAPES) - Finance Code 001.

\section{COMPETING INTERESTS}

Authors have declared that no competing interests exist.

\section{REFERENCES}

1. Johanson JF, Sonnenberg A. The prevalence of hemorrhoids and chronic constipation. An epidemiologic study. Gastroenterology. 1990;98(2):380-386.

DOI: 10.1016/0016-5085(90)90828-o

2. Lopes Filho LL, Lopes IMRS, Lopes LRS, Enokihara MMSS, Michalany AO, Matsunaga N. Mammary and extramammary Paget's disease. An Bras Dermatol. 2015;90(2):225-231.

DOI: 10.1590/abd1806-4841.20153189

3. Senagore AJ, Singer M, Abcarian $\mathrm{H}$, et al. A prospective, randomized, controlled multicenter trial comparing stapled hemorrhoidopexy and Ferguson hemorrhoidectomy: Perioperative and oneyear results. Dis Colon Rectum. 2004;47(11):1824-1836.

DOI: 10.1007/s10350-004-0694-9

4. Venara A, Podevin J, Godeberge P, et al. A comparison of surgical devices for grade II and III hemorrhoidal disease. Results from the LigaLongo Trial comparing transanal Doppler-guided hemorrhoidal artery ligation with mucopexy and circular stapled hemorrhoidopexy. Int J Colorectal Dis. 2018;33(10):1479-1483.

DOI: 10.1007/s00384-018-3093-8

5. Tainaka $T$, Uchida $H$, Tanaka $Y$, et al. Long-term outcomes and complications after laparoscopic-assisted anorectoplasty vs. posterior sagittal anorectoplasty for high- and intermediate-type anorectal malformation. Pediatr Surg Int. 2018;34(10):1111-1115.
DOI: 10.1007/s00383-018-4323-4

6. Zhang A-M, Chen M, Tang T-C, Qin D, Yue L, Zheng $H$. Somatosensory stimulation treatments for postoperative analgesia of mixed hemorrhoids: Protocol for a systematic review and network metaanalysis. Medicine (Baltimore). 2019;98(6): e14441.

DOI: 10.1097/MD.0000000000014441

7. Timmcke AE. The ASCRS textbook of colon and rectal surgery. Ochsner $\mathrm{J}$. 2007;7(1):48.

8. Dumlu EG, Gürer $A$, Tokaç $M$, et al. Hemorrhoidectomy in patients with grade III or IV disease: Harmonic scalpel compared with conventional closed technique. International Archives of Medicine. 2015;8.

DOI: $10.3823 / 1607$

9. Haas PA, Fox TA, Haas GP. The pathogenesis of hemorrhoids. Dis Colon Rectum. 1984;27(7):442-450.

DOI: $10.1007 / B F 02555533$

10. MacGregor JT, Heddle JA, Hite M, et al. Guidelines for the conduct of micronucleus assays in mammalian bone marrow erythrocytes. Mutat Res. 1987;189(2):103112.

DOI: 10.1016/0165-1218(87)90016-4

11. Smith LE. Hemorrhoidectomy with lasers and other contemporary modalities. Surg Clin North Am. 1992;72(3):665-679.

DOI: 10.1016/s0039-6109(16)45740-3

12. Wang JY, Chang-Chien CR, Chen JS, Lai $\mathrm{CR}$, Tang RP. The role of lasers in hemorrhoidectomy. Dis Colon Rectum. 1991;34(1):78-82.

DOI: $10.1007 / \mathrm{BF} 02050213$

13. Borba MR, Sobrado CW, Sokol S. Hemorroidectomia pela técnica fechada: Técnica de Sokol: Análise de 322 doentes. Rev Bras Colo-proctol. Published Online. 1997;98-100.

14. Parks AG. The surgical treatment of haemorrhoids. $\mathrm{Br}$ J. Surg. 1956;43(180): 337-351.

DOI: $10.1002 /$ bjs. 18004318002

15. Whitehead W. The surgical treatment of haemorrhoids. $\mathrm{Br}$ Med J. 1882;1(1101): 148-150.

DOI: 10.1136/bmj.1.1101.148

16. Wexner SD. The quest for painless surgical treatment of hemorrhoids 
continues. J Am Coll Surg. 2001;193(2): 174-178.

DOI: $10.1016 / \mathrm{s} 1072-7515(01) 00997-8$

17. Ferguson JA, Heaton JR. Closed hemorrhoidectomy. Dis Colon Rectum. 1959;2(2):176-179.

DOI: $10.1007 / \mathrm{BF} 02616713$

18. Soares MB, Pitombo MB, Paulo FL, et al. Hemorroidopexia por grampeamento parcial: Aspectos clínicos e impacto sob a fisiologia anorretal. Revista do Colégio Brasileiro de Cirurgiões. 2017;44(3):278283.

DOI: 10.1590/0100-69912017003010

19. Shao W-J, Li G-CH, Zhang ZH-K, Yang BL, Sun G-D, Chen Y-Q. Systematic review and meta-analysis of randomized controlled trials comparing stapled haemorrhoidopexy with conventional haemorrhoidectomy. $\mathrm{Br} \mathrm{J}$ Surg. 2008;95(2):147-160.

DOI: $10.1002 /$ bjs.6078

20. Ommer A, Hinrichs J, Möllenberg H, Marla $B$, Walz MK. Long-term results after stapled hemorrhoidopexy: A prospective study with a 6-year follow-up. Dis Colon Rectum. 2011;54(5):601-608.

DOI: 10.1007/DCR.0b013e3182098df2

21. Arroyo A, Pérez F, Miranda E, et al. Open versus closed day-case haemorrhoidectomy: Is there any difference? Results of a prospective randomised study. Int $\mathrm{J}$ Colorectal Dis. 2004;19(4):370-373.

DOI: 10.1007/s00384-003-0573-1

22. Bhatti MI, Sajid MS, Baig MK. MilliganMorgan (Open) versus Ferguson Haemorrhoidectomy (Closed): A systematic review and meta-analysis of published randomized, controlled trials. World J Surg. 2016;40(6):1509-1519.

DOI: 10.1007/s00268-016-3419-z

23. Cruz GMG da, Santana SKA de A, Santana JL, Ferreira RMRS, Neves PM, Faria MNZ de. Surgical complications of hemorrhoidectomy: A review of 76 cases. Revista Brasileira de Coloproctologia. 2007;27(1):42-57.

DOI: 10.1590/S0101-98802007000100007

24. Cristea C, Lewis CR. Hemorrhoidectomy. In: StatPearls. StatPearls Publishing; 2020.

(Accessed June 18, 2020)

Available:http://www.ncbi.nlm.nih.gov/book s/NBK549864/

25. Ganchrow MI, Mazier WP, Friend WG, Ferguson JA. Hemorrhoidectomy revisited- -a computer analysis of 2,038 cases. Dis Colon Rectum. 1971;14(2):128133.

DOI: $10.1007 / \mathrm{BF} 02560059$

26. Shaikh AR, Dalwani AG, Soomro N. An evaluation of Milligan-Morgan and Ferguson procedures for haemorrhoidectomy at Liaquat University Hospital Jamshoro, Hyderabad, Pakistan. Pak J Med Sci. 2013;29(1):122-127.

DOI: 10.12669/pjms.291.2858

27. Lu M, Shi G-Y, Wang G-Q, Wu Y, Liu Y, Wen $H$. Milligan-Morgan hemorrhoidectomy with anal cushion suspension and partial internal sphincter resection for circumferential mixed hemorrhoids. World J Gastroenterol. 2013;19(30):5011-5015.

DOI: 10.3748/wjg.v19.i30.5011

28. Marianelli R, Machado SPG, Almeida MG de, et al. Conventional hemorrhoidectomy versus stapled hemorrhoidopexy $(\mathrm{PPH})$ : $\mathrm{A}$ retrospective study of 253 patients. Revista Brasileira de Coloproctologia. 2009;29(1): 30-37.

DOI: $10.1590 / S 0101-98802009000100004$

29. Watson AJM, Hudson J, Wood J, et al. Comparison of stapled haemorrhoidopexy with traditional excisional surgery for haemorrhoidal disease (eTHoS): A pragmatic, multicentre, randomised controlled trial. Lancet. 2016;388(10058): 2375-2385.

DOI: 10.1016/S0140-6736(16)31803-7

30. Jayaraman S, Colquhoun PHD, Malthaner RA. Stapled versus conventional surgery for hemorrhoids. Cochrane Database Syst Rev. 2006;4:CD005393.

DOI: 10.1002/14651858.CD005393.pub2

31. Pandini LC, Nahas SC, Nahas CSR, Marques CFS, Sobrado CW, Kiss DR. Surgical treatment of haemorrhoidal disease with $\mathrm{CO}_{2}$ laser and MilliganMorgan cold scalpel technique. Colorectal Dis. 2006;8(7):592-595.

DOI: 10.1111/j.1463-1318.2006.01023.x

32. Madoff RD, Fleshman JW, Clinical Practice Committee, American Gastroenterological Association. American Gastroenterological Association technical review on the diagnosis and treatment of hemorrhoids. 2004;126(5):1463-1473

DOI: 10.1053/j.gastro.2004.03.008

33. Nienhuijs S, de Hingh I. Conventional versus LigaSure hemorrhoidectomy for patients with symptomatic hemorrhoids. 
Cochrane Database Syst Rev. hemorrhoidectomy by LigaSure with 2009;1:CD006761. conventional Milligan Morgan's DOI: 10.1002/14651858.CD006761.pub2 hemorrhoidectomy. Pak J Med Sci. 34. Bakhtiar N, Moosa FA, Jaleel F, Qureshi 2016;32(3):657-661.

NA, Jawaid M. Comparison of DOI: 10.12669/pjms.323.9976

(c) 2020 Coelho et al.; This is an Open Access article distributed under the terms of the Creative Commons Attribution License (http://creativecommons.org/licenses/by/4.0), which permits unrestricted use, distribution, and reproduction in any medium, provided the original work is properly cited.

Peer-review history:

The peer review history for this paper can be accessed here: http://www.sdiarticle4.com/review-history/58712 